\title{
Participação Popular no Licenciamento de Atividades Causadoras de Significativo Impacto Ambiental
}

\author{
Popular Participation in Licensing of Activities Cause of Significant Environment \\ Impact
}

\author{
Bruno Quiquinato Ribeiro ${ }^{1}$ \\ Ana Claudia Duarte Pinheiro ${ }^{2}$
}

\section{Resumo}

O presente artigo apresenta os contornos do direito à participação popular no licenciamento de atividades causadoras de significativo impacto ambiental no Direito Ambiental Brasileiro. Analisa os critérios legais e constitucionais relativos ao direito em tela. Interpreta o sistema normativo conforme a Constituição Federal. Destaca a importância da publicidade para que a participação popular seja efetiva. Fundamenta a participação popular no Texto Constitucional, erigida à categoria de garantia fundamental, cuja ausência torna absolutamente nula a licença ambiental concedida. Relaciona o direito em questão à democracia participativa e ao livrearbítrio na escolha do modelo de desenvolvimento econômico, trazendo e comentando exemplos práticos relativos ao tema.

Palavras-Chave: Participação Popular. Licenciamento de atividades Causadoras de significativo impacto ambiental. Publicidade.

\begin{abstract}
This article presents the contours of the right to popular participation in the licensing of activities that cause significant environmental impact in Brazilian Environmental Law. Examines the constitutional and statutory criteria relating to the right on screen. Interprets the regulatory system as the Federal Constitution. Stresses the importance of advertising for that popular participation is effective. Based popular participation in the Constitutional Text, erected to the category of fundamental guarantee, whose absence makes absolutely zero environmental license granted. The right in question relates to participatory democracy and the free will to choose the model of economic development, providing practical examples and commenting on the subject.
\end{abstract}

Keywords: Popular Participation. Licensing activities cause significant environmental impact. Advertising.

\footnotetext{
${ }^{1}$ Bacharel em Direito pela Universidade Estadual de Londrina (2001-2005). Servidor do Ministério Público Federal de Londrina (desde 2007)

${ }^{2}$ Professora da Universidade Estadual de Londrina - graduação e pós-graduação nas disciplinas de Direito Ambiental e Urbanístico, Teoria Geral do Processo e Direito Financeiro. Mestre em Direito Negocial pela UEL.
} 


\section{Introdução}

O presente artigo discorre sobre o direito à informação e à participação popular no processo ambiental de licenciamento de obras e atividades causadoras de significativo impacto ambiental.

Referidos direitos vêm previstos na Constituição Federal (CF) como direitos fundamentais (CF, art. $5^{\circ}$, incisos XIV, XXXIII e XXXIV, alínea "a"), e são insuprimíveis (CF, art. $60, \S 4^{\circ}$, inciso IV).

No Estado Democrático de Direito, apresentam-se de forma indissociável. Paulo Affonso Leme Machado (2004, p. 78) ensina-nos que "A informação serve para o processo de educação de cada pessoa e da comunidade. Mas a informação visa, também, a dar chance à pessoa informada de tomar posição ou pronunciar-se sobre a matéria informada."

Neste raciocínio, o referido processo de licenciamento ambiental deve propiciar à população situada na área de influência da obra todas as informações e estudos ambientais disponíveis, além dos meios adequados para que participe do empreendimento, dando sugestões e críticas, cujo objetivo é oferecer à Administração Ambiental o substrato para emitir parecer favorável ou contrário à atividade.

O envolvimento da população no processo ambiental justifica-se na medida em que o conceito de significativo impacto ambiental depende de vários fatores, dentre os quais a escala de valores das pessoas. Neste prisma, um exemplo prático se destaca com o projeto de expansão da mina de fosfato de Araxá/MG foi barrado pelo órgão ambiental, em razão da pressão da população, que prezava o local pelo lazer que proporcionava (SÁNCHEZ, 2006, p. 139).

Através da análise das normas constitucionais, principiológicas, legais e infra-legais acerca do tema, nota-se o surgimento de tensão entre dois modelos de processo ambiental: o modelo deliberativo, que incita a ampliar o leque de questões estudadas, buscando construir consensos que possam durar até o final da avaliação de impactos; o modelo tecnocrático de eficiência do processo decisório, cuja preocupação é com os prazos e custos, o qual implica pequena ou insignificativa participação popular (SÁNCHEZ, 2006, p. 140). Propor-se-á solução que resolva a referida colisão de modelos, cuja implementação passa pela participação popular no processo ambiental. 


\section{O Processo Ambiental de Licenciamento e a Participação Popular}

Toda obra ou atividade potencialmente causadora de significativa degradação do meio ambiente deve passar por processo administrativo ambiental, que permitirá ou não a obra/atividade, com ou sem condicionantes (condicionante refere-se a permissão da atividade, cuja execução só pode ocorrer com determinadas restrições impostas pelo órgão ambiental, para o mínimo impacto ambiental possível).

As fases deste processo encontram-se no art. 10 da Resolução 237/97 do Conselho Nacional do Meio Ambiente - CONAMA (1997), abaixo transcrito:

Art. 10 - O procedimento de licenciamento ambiental obedecerá às seguintes etapas:

I - Definição pelo órgão ambiental competente, com a participação do empreendedor, dos documentos, projetos e estudos ambientais, necessários ao início do processo de licenciamento correspondente à licença a ser requerida;

II - Requerimento da licença ambiental pelo empreendedor, acompanhado dos documentos, projetos e estudos ambientais pertinentes, dando-se a devida publicidade;

III - Análise pelo órgão ambiental competente, integrante do SISNAMA, dos documentos, projetos e estudos ambientais apresentados e a realização de vistorias técnicas, quando necessárias;

IV - Solicitação de esclarecimentos e complementações pelo órgão ambiental competente, integrante do SISNAMA, uma única vez, em decorrência da análise dos documentos, projetos e estudos ambientais apresentados, quando couber, podendo haver a reiteração da mesma solicitação caso os esclarecimentos e complementações não tenham sido satisfatórios;

V - Audiência pública, quando couber, de acordo com a regulamentação pertinente;

VI - Solicitação de esclarecimentos e complementações pelo órgão ambiental competente, decorrentes de audiências públicas, quando couber, podendo haver reiteração da solicitação quando os esclarecimentos e complementações não tenham sido satisfatórios;

VII - Emissão de parecer técnico conclusivo e, quando couber, parecer jurídico;

VIII - Deferimento ou indeferimento do pedido de licença, dando-se a devida publicidade.

Na primeira fase, o proponente solicita a permissão da obra ou atividade de significativo impacto ambiental. O órgão ambiental elabora o chamado "Termo de Referência", descrito no inciso I do art. 10 da Resolução acima, e determina ao proponente a apresentação de estudos, projetos e documentos que julgar necessários para a licença ambiental. Ver-se-á depois que tais documentos materializam-se com a entrega do Estudo Prévio de Impacto Ambiental (EPIA) e correlato Relatório de Impacto Ambiental (RIMA), segunda fase do processo de licenciamento. 
Nesta fase já estão previstos os direitos à informação e participação popular. Consoante artigo 11, § 2º, da Resolução 01/86 do CONAMA: "Ao determinar a execução do EPIA e apresentação do RIMA, o órgão estadual competente ou o IBAMA ou, quando couber, o Município, determinará prazo para recebimento dos comentários a serem feitos pelos órgãos públicos e demais interessados [...]"

O órgão ambiental, no "Termo de Referência", determina ao proponente a realização do EPIA, ao mesmo tempo em que abre prazo à população para comentários, com o fim de colher sugestões para que o EPIA seja o mais abrangente possível. É como se a população formulasse um EPIA paralelo ao EPIA do proponente. É o que ensina Paulo Affonso Leme Machado, ao comentar o Decreto 26.687 da Bahia (MACHADO, 2004, p. 239):

\begin{abstract}
No Estado da Bahia o Decreto 26.687, de 11.2.1982, prevê em seu art. 93, caput: Para as atividades sujeitas ao Sistema de Licenciamento caberá à CRA realizar o Estudo Preliminar do Impacto Ambiental, cujo resultado poderá ser: I - resultado de impacto não significativo; II - resultado de impacto significativo, quando o interessado deverá: a) publicar, através de órgãos de comunicação da imprensa, declaração sobre o projeto que pretenda implantar, requerendo os comentários da comunidade, num prazo de 45 dias, tempo em que colocará o projeto à disposição dos interessados em local e hora claramente divulgados. A regulamentação baiana prevê um tipo especial de comentário, que será realizado antes do EPIA da equipe multidisciplinar. Portanto, no Estado da Bahia, de forma elogiável, deverão ser levadas a efeito duas fases de comentários: antes do EPIA e depois deste. Assinalese que a fixação do período de 45 dias dará chance dos interessados tomarem conhecimento do projeto e de passarem a acompanhar a elaboração do EPIA.
\end{abstract}

Na segunda fase, o proponente, de posse das exigências contidas no "Termo de Referência", elabora o EPIA, do qual faz parte o RIMA, nos quais elenca os possíveis impactos positivos e negativos da obra, pontuando as medidas compensatórias e tecnologias aptas a neutralizar ou diminuir os impactos. A etapa está prevista no art. 10, II, da Resolução 237/97 do CONAMA.

Nesta fase, os direitos à informação e à participação popular iniciam-se quando o proponente entrega à Administração o EPIA/RIMA, requerendo licença ambiental, momento no qual, consoante artigo $225, \S 1$ 으, IV, da CF, dar-se-á publicidade, e, na dicção do art. 10 , § 1으, da Lei 6.938/81, o pedido de licenciamento será publicado no jornal oficial do Estado, bem como em periódico regional ou local de grande circulação. Transcrevem-se as normas: 
Art. 225. Todos têm direito ao meio ambiente ecologicamente equilibrado, bem de uso comum do povo e essencial à sadia qualidade de vida, impondo-se ao Poder Público e à coletividade o dever de defendê-lo e preservá-lo para as presentes e futuras gerações.

$\S 1$ Para assegurar a efetividade desse direito, incumbe ao Poder Público:

[...]

IV - exigir, na forma da lei, para instalação de obra ou atividade potencialmente causadora de significativa degradação do meio ambiente, estudo prévio de impacto ambiental, a que se dará publicidade (BRASIL, 1988).

Art. 10 - A construção, instalação, ampliação e funcionamento de estabelecimentos e atividades utilizadoras de recursos ambientais, considerados efetiva e potencialmente poluidores, bem como os capazes, sob qualquer forma, de causar degradação ambiental, dependerão de prévio licenciamento de órgão estadual competente, integrante do Sistema Nacional do Meio Ambiente - SISNAMA, e do Instituto Brasileiro do Meio Ambiente e Recursos Naturais Renováveis - IBAMA, em caráter supletivo, sem prejuízo de outras licenças exigíveis. (Redação dada pela Lei no 7.804, de 1989).

$\S 1$ 으 - Os pedidos de licenciamento, sua renovação e a respectiva concessão serão publicados no jornal oficial do Estado, bem como em um periódico regional ou local de grande circulação (BRASIL, 1989, grifo nosso).

A participação popular, nesta fase, não se perfaz somente com a publicidade do EPIA/RIMA, mas também com o conteúdo do RIMA.

Deve-se esclarecer que o EPIA é um documento técnico-científico de estudo de impactos ambientais, muitas vezes com linguagem inacessível à população. Por outro lado, o RIMA é um resumo não técnico do EPIA, sintetiza as conclusões deste e facilita a compreensão das consequências do projeto. No Brasil, o RIMA não costuma ser submetido ao crivo governamental, de forma que a coerência entre ele e sua base - EPIA, fica ao arbítrio do proponente. Muitos RIMAs são elaborados de forma burocrática e apressada, com supressão de parágrafos e seções do EPIA, sem coerência com ele (SÁNCHEZ, 2006, p. 140). Neste caso, imperiosa a não aceitação do RIMA pela Administração Ambiental, ou, caso aceito e expedida a licença, esta será nula. A razão disto é a afronta ao direito de participação popular, eis que um RIMA não coerente, "faltando pedaços", restringirá o acesso da sociedade à informação ambiental.

No tocante à publicidade do EPIA/RIMA, deve abranger todos os municípios, mais do que isso, todos os indivíduos potencialmente atingidos pelo empreendimento, coincidindo com a bacia hidrográfica onde localizado o projeto. A abrangência da publicação guarda lógica com a própria extensão do EPIA/RIMA, que deverá “definir os limites da área geográfica a ser direta ou indiretamente afetada pelos impactos, denominada área de 
influência do objeto, considerando em todos os casos, a bacia hidrográfica na qual se localiza" (art. 5o, III, da Resolução 01/86) (CONAMA, 1997).

Diz-se que a publicidade do EPIA/RIMA deve englobar não somente todos os municípios, mas também todos os moradores ao redor da bacia hidrográfica, porque eventual publicação da entrega do documento em jornal de circulação estadual, ou mesmo municipal, pode não ser o suficiente para dar publicidade à população ribeirinha/rural/indígena, caso em que a publicidade deve ser realizada de outras maneiras (via rádio, internet, comunicação verbal realizada por agentes públicos, comunicação visual - cartazes, jornais locais, regionais e oficiais, dentre outras formas).

Além disso, o princípio da democracia participativa pode ser conseguido com mais eficácia quando a publicação do EPIA/RIMA for dirigida diretamente aos órgãos públicos que manifestarem interesse, ou tiverem relação direta com o projeto ${ }^{3}$.

A Resolução 06/86 do CONAMA estabeleceu os modelos de publicação de pedidos de licenciamento apenas em periódicos e Diário Oficial do Estado, insuficientes para a efetiva publicidade do empreendimento, razão pela qual a Administração Pública determinará que a publicidade seja veiculada também pelos meios antes referidos. A fixação de modelos de publicação pela referida Resolução não representa taxatividade, mas exemplificação.

Ainda sobre a publicidade, dispõe o art. 11, caput, da Resolução 01/86 - CONAMA (1986), sobre o RIMA, que "Suas cópias permanecerão à disposição dos interessados, nos centros de documentação ou bibliotecas do IBAMA e do órgão estadual de controle ambiental correspondente, inclusive no período de análise técnica". Sendo o EPIA/RIMA determinado pelo Município, torna-se claro que ficará disponível nos centros de comunicação municipal existentes.

Neste ponto, em complementação às normas acima, o EPIA/RIMA deve ser disponibilizado também nos sítios eletrônicos das partes envolvidas: Órgãos Ambientais e Proponente. A utilização da internet, dada a facilidade com que as informações são disseminadas, consubstancia-se em ferramenta essencial a dar publicidade nos processos ambientais, não podendo ser dispensada pela Administração Pública.

\footnotetext{
3 Art. 11, § 1으, da Resolução 001/86 do CONAMA: "Os órgãos públicos que manifestarem interesse, ou tiverem relação direta com o projeto, receberão cópia do RIMA, para conhecimento e manifestação".
} 
Na ação civil pública no 2007.70.01.006835-9, que tramitou na 1a Vara Federal de Londrina, outro importante exemplo a ser destacado e cuja exordial visava discutir a questão da participação popular na tomada de decisões ambientais, o Juízo, corroborando o ponto de vista acima, determinou na parte dispositiva da sentença:

Ante o exposto, a) julgo extinto o processo, sem julgamento de mérito, no que tange ao pedido de suspensão do procedimento de licenciamento ambiental da UHE Mauá até que seja concluída a Avaliação Ambiental Integrada da Bacia do Rio Tibagi; b) no que resta, julgo parcialmente procedentes os pedidos formulados na inicial, com base no art. 269, inciso I do Código de Processo Civil, para que: a) no prazo de 40 (quarenta) dias, o IAP disponibilize em seu sítio na internet (ainda que por meio de "links"), com fácil acesso, todos os estudos referentes à Usina Hidrelétrica de Mauá utilizados em seu licenciamento ambiental; todas as licenças ambientais concedidas referentes à UHE Mauá; e todos os programas de proteção ou compensação social ou ambiental referentes ao empreendimento, com informação atualizada do andamento de cada um (a qual deve ser fornecida pelo empreendedor ao IAP, caso o IAP não tenha a informação). b) no prazo de 40 (quarenta) dias, o Consórcio Energético Cruzeiro do Sul disponibilize em sítio na internet (que pode ser próprio ou do seu sócio majoritário), com fácil acesso, cronograma da obra de instalação da UHE Mauá, inclusive relatando o seu andamento, de forma atualizada - também o fazendo no que tange às medidas e programas referentes aos atingidos pelo empreendimento e de proteção/compensação social/ambiental. Deverá também disponibilizar, se ainda não o fez, telefone, "e-mail" e pessoa responsável para recebimento de pedidos e reclamações de atingidos pelo empreendimento. c) os réus (inclusive o IBAMA, no âmbito de sua competência supletiva) atendam aos pedidos de esclarecimentos ou informações efetuados pelo Ministério Público Federal ou demais legitimados à propositura de ação civil pública, referentes ao empreendimento UHE Mauá, em prazo razoável. d) os interessados em geral, especialmente os diretamente atingidos pelo empreendimento, possam pleitear junto aos réus (inclusive ao IBAMA, no âmbito de sua competência supletiva), no que tange ao empreendimento UHE Mauá, através do MPF ou dos demais legitimados à propositura de ação civil pública. Sem custas e honorários, nos termos do art. 18 da Lei 7.347/85 (BRASIL, 2009a).

A terceira fase do processo de licenciamento, inserida no art. 10, III e IV, da Resolução 237/97 do CONAMA, inicia-se quando o órgão licenciador recebe o EPIA/RIMA e demais documentos, podendo exigir esclarecimentos e complementações, ou não, caso em que a licença estará prestes a ser expedida.

Prestados os esclarecimentos e complementações, ou não havendo necessidade deles, inicia-se a penúltima e quarta fase, disposta no art. 10, V e VI, da mencionada Resolução.

Trata-se das Audiências Públicas, as quais, incorretamente regulamentadas pelo CONAMA, "serão realizadas, quando couber, de acordo com a regulamentação pertinente". 
As Audiências Públicas não se submetem à expressão "quando couber". Não são facultativas.

Dois princípios permitem o raciocínio de obrigatoriedade das Audiências Públicas: o princípio da publicidade e o princípio da democracia participativa nas decisões administrativas.

Segundo o princípio da publicidade, encontrado no art. 37, caput, da CF, o administrador público deve zelar pela transparência em seus comportamentos (MELLO, 2006, p. 102).

De outro giro, o art. 1으, parágrafo único, e 14, ambos da CF, permitem-nos concluir que o povo exerce o poder indiretamente através de seus representantes, bem como participa direta e concretamente no controle dos atos estatais (LENZA, 2007, p. 667). É o princípio da democracia participativa.

Encontram-se os dois princípios conjugados num só artigo da CF. O art. 5ㅇ, incisos XIV, XXXIII e XXXIV, alínea "a", confere ao indivíduo o direito de ser informado e de participar nas decisões estatais que lhe afetem:

XIV - é assegurado a todos o acesso à informação e resguardado o sigilo da fonte, quando necessário ao exercício profissional.

XXXIII - todos têm direito a receber dos órgãos públicos informações de seu interesse particular, ou de interesse coletivo ou geral, que serão prestadas no prazo da lei, sob pena de responsabilidade, ressalvadas aquelas cujo sigilo seja imprescindível à segurança da sociedade e do Estado.

XXXIV - são a todos assegurados, independentemente do pagamento de taxas:

a) o direito de petição aos Poderes Públicos em defesa de direitos ou contra ilegalidade ou abuso de poder (BRASIL, 1988).

Além disso, a participação popular no processo ambiental de atividades de significativo impacto ambiental é uma exigência que decorre da natureza pública do processo ambiental (SILVA, 2003, p. 297).

No tocante à legislação infraconstitucional, a Lei 6.938/81 assim dispõe:

Art. 4으- A Política Nacional do Meio Ambiente visará:

[...]

V - à difusão de tecnologias de manejo do meio ambiente, à divulgação de dados e informações ambientais e à formação de uma consciência pública sobre a necessidade de preservação da qualidade ambiental e do equilíbrio ecológico; 
Art. 8ㅇ Compete ao CONAMA:

[...]

II - determinar, quando julgar necessário, a realização de estudos das alternativas e das possíveis consequências ambientais de projetos públicos ou privados, requisitando aos órgãos federais, estaduais e municipais, bem assim a entidades privadas, as informações indispensáveis para apreciação dos estudos de impacto ambiental, e respectivos relatórios, no caso de obras ou atividades de significativa degradação ambiental, especialmente nas áreas consideradas patrimônio nacional.

Art. 9o - São instrumentos da Política Nacional do Meio Ambiente:

$[\ldots]$

XI - a garantia da prestação de informações relativas ao Meio Ambiente, obrigandose o Poder Público a produzi-las, quando inexistentes;

Art. 10 - A construção, instalação, ampliação e funcionamento de estabelecimentos e atividades utilizadoras de recursos ambientais, considerados efetiva e potencialmente poluidores, bem como os capazes, sob qualquer forma, de causar degradação ambiental, dependerão de prévio licenciamento de órgão estadual competente, integrante do Sistema Nacional do Meio Ambiente - SISNAMA, e do Instituto Brasileiro do Meio Ambiente e Recursos Naturais Renováveis - IBAMA, em caráter supletivo, sem prejuízo de outras licenças exigíveis.

$\S 1$ 으 - Os pedidos de licenciamento, sua renovação e a respectiva concessão serão publicados no jornal oficial do Estado, bem como em um periódico regional ou local de grande circulação (BRASIL, 1981).

Verifica-se, portanto, que o arcabouço normativo garante o direito à informação e à participação popular no processo ambiental brasileiro, de modo que a realização de Audiências Públicas é uma garantia constitucional-legal, e não pode ser dispensada.

\section{Instrumentalização da Participação Popular}

Como se viu, a normatização vigente demonstra a existência de três momentos de participação popular no processo ambiental. O primeiro, por ocasião do "Termo de Referência"; o segundo, quando o EPIA/RIMA é entregue; o terceiro, exatamente antes da Administração Ambiental emitir a Licença Prévia - fase de Audiências Públicas.

A participação popular nas duas primeiras fases do licenciamento ambiental é fundamental para o válido desenrolar do processo. Quanto mais cedo a população participar, mais cedo as soluções serão encontradas, e menor custo haverá para o proponente (SÁNCHEZ, 2006, p. 140).

Entretanto, caso os dois primeiros momentos de participação popular não ocorram da maneira adequada, a garantia democrática ainda pode ser exercida na terceira fase - 
Audiências Públicas. Neste diapasão, defende-se que os dois primeiros momentos levam apenas à nulidade relativa do processo ambiental.

De outra sorte, as Audiências Públicas não podem ser suprimidas, sob pena de nulidade absoluta do processo ambiental.

Tal afirmativa é corroborada na medida em que a participação popular no processo só poderá ser entendida como efetiva quando todos os estudos e indagações técnicas forem travadas entre proponente e Administração Ambiental, momento no qual os indivíduos atingidos poderão visualizar com a maior amplitude possível os impactos ambientais da obra/atividade. Como as Audiências Públicas ocorrem no último momento antes da expedição ou denegação da licença ambiental, a participação popular é atendida de forma mais satisfatória.

Neste sentido, colaciona-se recente julgado:

APELAÇÃO/REEXAME NECESSÁRIO. PROCESSO 2001.71.01.001497-1. UF: RS. ÓRGÃO JULGADOR: QUARTA TURMA. RELATORA: Des. Federal MARGA INGE BARTH TESSLER. DATA DA DECISÃO: 01.04.2009. TRIBUNAL REGIONAL FEDERAL DA 4a REGIÃO.

EMENTA PROCESSO CIVIL. DIREITO AMBIENTAL. AÇÃO CIVIL PÚBLICA. REEXAME NECESSÁRIO. PERDA DO OBJETO. HONORÁRIOS. 1. No que se refere à suposta perda de objeto, efetivamente tal não ocorreu, já que, como bem evidenciado, trata-se de dois aspectos, Complexo Mineiro e Complexo Industrial, e apenas com relação ao último é que o Grupo Paranapanema, em 19.03.2003, desistiu de sua implantação "na forma originalmente formulada pelo Reg. 2147. Resta a questão do Complexo Mineiro, e quiçá, um novo encaminhamento do outro projeto, assim, o objeto da demanda permanece íntegro, não havendo motivo para declarar-se perda do objeto. 2. Na questão de fundo, é de ser mantida a sentença, pois realizar audiência pública sem antes promover estudos determinaria uma consulta popular sem conhecimentos técnicos suficientes, a população sequer teria sido convenientemente informada sobre a discussão dos impactos que a região sofreria. É o princípio da informação e publicidade que precisa ser assegurado de forma correta e consistente. Participação desinformada equivale a participação nula. 3. Merece provimento o apelo apenas no que se refere à condenação em honorários imposta ao Ibama, pois não é o caso de lei de regência. ACÓRDÃO Vistos e relatados estes autos em que são partes as acima indicadas, decide a Egrégia 4ạ Turma do Tribunal Regional Federal da 4a $\underline{\text { a Região, por }}$ unanimidade, dar parcial provimento ao apelo do Ibama, no que respeita à condenação em honorários, afastando-a, e negar provimento à remessa oficial, nos termos do relatório, votos e notas taquigráficas que ficam fazendo parte integrante do presente julgado (BRASIL,2009b) 
A Resolução 09/87 do CONAMA regula especificamente o instituto das Audiências Públicas, da seguinte forma:

Resolução CONAMA № 9, de 03 de dezembro de 1987

O CONSELHO NACIONAL DO MEIO AMBIENTE - CONAMA, no uso das atribuições que lhe conferem o Inciso II. do art. 70 do Decreto no 88.351, de 10 de julho de 1983, e tendo em vista o disposto na RESOLUÇÃO/CONAMA no 1, de 23 de janeiro de 1986.

RESOLVE:

Art. 1․ . A Audiência Pública referida na RESOLUÇÃO CONAMA no 1/86, tem por finalidade expor aos interessados o conteúdo do produto em análise e do seu referido RIMA, dirimindo dúvidas e recolhendo dos presentes as críticas e sugestões a respeito. Art. 2ㅇ. Sempre que julgar necessário, ou quando for solicitado pôr entidade civil, pelo Ministério Público, ou por 50 (cinqüenta) ou mais cidadãos, o Órgão do Meio Ambiente promoverá a realização de Audiência Pública. $\S 1$ ㅇ. O Órgão de Meio Ambiente, a partir da data do recebimento do RIMA, fixará em edital e anunciará pela imprensa local a abertura do prazo que será no mínimo de 45 dias para solicitação de audiência pública.

$\S 2^{\circ}$. No caso de haver solicitação de audiência pública e na hipótese do Órgão Estadual não realizá-la, a licença não terá validade.

§ 3‥ Após este prazo, a convocação será feita pelo Órgão licenciador, através de correspondência registrada aos solicitantes e da divulgação em órgãos da imprensa local.

$\S 40$. A audiência pública deverá ocorrer em local acessível aos interessados.

$\S 5$. . Em função da localização geográfica dos solicitantes se da complexidade do tema, poderá haver mais de uma audiência pública sobre o mesmo projeto e respectivo Relatório de Impacto Ambiental - RIMA.

Art. 3 . A audiência pública será dirigida pelo representante do Órgão licenciador que, após a exposição objetiva do projeto e o seu respectivo RIMA, abrirá as discussões com os interessados presentes.

Art. 40 . Ao final de cada audiência pública lavrada uma ata sucinta.

Parágrafo único . Serão anexadas à ata, todos os documentos escritos e assinados que forem entregues ao presidente dos trabalhos durante a seção.

Art. 5o . A ata da(s) Audiência(s) Pública(s) e seus anexos, servirão de base, juntamente com o RIMA, para a análise e parecer final do licenciador quanto à aprovação ou não do projeto.

Art. 60 . Esta resolução entra em vigor na data de sua publicação (CONAMA, 1987).

Conforme argumentação anterior, a leitura do art. 2o da referida Resolução aponta para a necessidade de se fazer uma interpretação conforme a Constituição Federal. As Audiências Públicas, última etapa antes da licença ambiental, sempre são necessárias. Inexiste, portanto, neste ponto, a discricionariedade para determinar sua realização sempre que se julgar necessário. 
No mesmo sentido, quando o $\S 2$ 을 do art. 2ㅇ dispõe que "No caso de haver solicitação de audiência pública e na hipótese do Órgão Estadual não realizá-la, a licença não terá validade", o texto deve passar pela interpretação conforme a Constituição Federal, para dispor que, não havendo Audiências Públicas (implicitamente são obrigatórias), a licença não terá validade.

Édis Milaré destaca a Constituição do Estado de São Paulo, que em seu artigo 192, § 2o (em vigor), dispõe que as audiências públicas são obrigatórias (MILARÉ, 2001, p. 325):

Art. 192 A execução de obras, atividades, processos produtivos e empreendimentos e a exploração de recursos naturais de qualquer espécie, quer pelo setor público, quer pelo privado, serão admitidas se houver resguardo do meio ambiente ecologicamente equilibrado.

[...] omissis

$\S$ 2ㅇ. A licença ambiental, renovável na forma da lei, para a execução e a exploração mencionadas no caput deste artigo, quando potencialmente causadoras de significativa degradação do meio ambiente, será sempre precedida, conforme critérios que a legislação especificar, da aprovação do Estudo Prévio de Impacto Ambiental e respectivo relatório a que se dará publicidade, garantida a realização de audiências públicas" (grifo Nosso)

Nos termos do art. 2o, $\S 19$, da Resolução 09/87 do CONAMA, as Audiências Públicas serão realizadas no prazo mínimo de 45 dias entre a publicação e sua efetiva realização.

E mais, a publicação do edital de audiência pública deve ser amplo, na forma defendida alhures. O conteúdo da publicação deve ser preciso, informando, essencialmente, onde todos os documentos relativos ao processo ambiental possam ser acessados livremente por quaisquer pessoas ${ }^{4}$, cobrando-se apenas o custo de eventual oferecimento de cópias reprográficas.

4 Consoante art. $17, \S 3$ 으, do Decreto 99.274/90, as informações que constituam sigilo industrial não devem ser repassadas à população. 


\section{Conclusão}

Os direitos à informação e à participação popular no processo ambiental de licenciamento de atividades significativamente impactantes estão consolidados no ordenamento jurídico. Possuem status constitucional de garantia fundamental, insuprimíveis, portanto.

A forma como são exercitados está disciplinada na Lei 6.938/81 e Resoluções 01/86, 09/87 e 237/97, todas do CONAMA.

Todas as fases onde a participação popular é inserida são importantes, e quanto mais cedo as autoridades públicas propiciarem-na, melhor será o resultado tanto para o setor econômico quanto para o meio ambiente e população.

A fase que se mostra de grande importância é a de Audiências Públicas (art. 10, incisos V e VI, da Resolução 237/97 do CONAMA), que ocorre no final do processo de licenciamento, momento no qual todas as informações encontram-se à disposição da população.

Entretanto, a participação popular só existe na medida em que for efetiva, e para que a efetividade seja garantida, deve-se disponibilizar meios adequados de publicidade e debates com a população atingida. Tais meios são os seguintes: ampla divulgação das Audiências Públicas através da internet, rádio, comunicação verbal feita por funcionários públicos, comunicação visual - cartazes, jornais locais, regionais e oficiais; direcionamento da publicidade para todos os indivíduos atingidos direta e indiretamente pela obra, incluindo-se órgãos públicos; designação das audiências em locais de fácil acesso, em dia e horários que permitam longo debate, podendo ser realizada mais de uma audiência, conforme art. $2^{\circ}, \S$ $5^{\circ}$, da Resolução 09/87 do CONAMA; disponibilização de todos os documentos, estudos técnicos e informações à população através da internet ("sites" dos proponentes e Órgão Licenciador) e em centros locais e regionais de documentação (o edital de audiência pública deve informar onde os documentos podem ser obtidos), propiciando-se a extração de cópias com preços acessíveis; prazo mínimo de 45 dias entre a publicidade da audiência e sua efetiva realização.

Respeitados os critérios acima defendidos para a qualidade das Audiências Públicas, as quais são de realização obrigatória no último momento antes da expedição ou denegação de licença ambiental, entende-se que o direito à participação popular foi efetivamente garantido, convalidando-se eventuais vícios nas fases anteriores. 
A participação popular não pode ser vista como empecilho pela Administração Ambiental e proponente. O modelo tecnocrático, de obtenção de resultados rápidos com poucos custos deve ceder ante o direito fundamental de ser informado e de participar das decisões estatais, uma vez que traduzem mais do que meros conceitos, mas alcançam os valores da sociedade. Referido direito, por sua vez, não existe de per si. Visa criar condições ao meio ambiente ecologicamente equilibrado (CF, art. 225), formar consciência pública sobre a necessidade de preservação da qualidade ambiental e do equilíbrio ecológico (art. 4으, V, da Lei 6.938/81), fortalecer a democracia participativa (CF, art. 1o, parágrafo único) e propiciar à população opinar, paralelamente ao setor empresarial, sobre o modelo de desenvolvimento econômico que melhor se adapte ao meio ambiente e à cultura brasileira.

\section{Referências}

BRASIL. Constituição (1988). Constituição da República Federativa do Brasil. Disponível em: <http://www.planalto.gov.br/ccivil_03/Constituicao/Constituiçao.htm>. Acesso em: out. 2010.

BRASIL. Lei no 6.938, de 31 de agosto de 1981. Dispõe sobre a Política Nacional do Meio Ambiente, seus fins e mecanismos de formulação e aplicação, e dá outras providências. Disponível em: < http://www.planalto.gov.br/ccivil/Leis/L6938org.htm>. Acesso em: out. 2010.

BRASIL. Tribunal Regional Federal (4. Região). Apelação Cível no 0006835-57.2007.404.7001. Indenização por Dano Ambiental. Juiz: Roberto Lima Santos. Órgão Julgador: Juízo Substituto da 01a VF de Londrina. 2009.Disponível em: <http://www.trf4.jus.br/trf4/>. Acesso em: 25 nov. 2009a.

BRASIL. Tribunal Regional Federal (4. Região). Processo 2001.71.01.001497-1. UF: RS. Órgão julgador: quarta turma. Relatora: Des. Federal Marga Inge Barth Tessler. Data da Decisão: 01.04.2009. Disponível em: <http://www.trf4.jus.br/trf4/>. Acesso em: 25 nov. 2009b.

CONSELHO NACIONAL DO MEIO AMBIENTE - CONAMA. Resolução 237/97. Disponível em: <http://www.mma.gov.br/port/conama/res/res97/res23797.html>. Acesso em: 25 nov. 2009.

CONSELHO NACIONAL DO MEIO AMBIENTE - CONAMA. Resolução Conama $n^{\circ} 001$ de 23.01.86 EIA/RIMA. Disponível em: <http://www.mma.gov.br/port/conama/legiabre.cfm? codlegi=23>. Acesso em: 25 nov. 2009.

LENZA, Pedro. Direito constitucional esquematizado. 11. ed. São Paulo: Método, 2007. 
MACHADO. Paulo Affonso Leme. Direito ambiental brasileiro. 12. ed. São Paulo: Malheiros Editores, 2004.

MELLO, Celso Antônio Bandeira de. Curso de direito administrativo. 20. ed. São Paulo: Malheiros, 2006.

MILARÉ, Édis. Direito do ambiente: doutrina, prática, jurisprudência, glossário. 2. ed. São Paulo: Revista dos Tribunais, 2001.

SÁNCHEZ, Luis Enrique. Avaliação de impacto ambiental: conceitos e métodos. São Paulo: Oficina de Textos, 2006.

SILVA, José Afonso da. Direito ambiental constitucional. 4. ed. São Paulo: Malheiros, 2003. 